\title{
Application of Signal Analysis to the Climate
}

\author{
Peter Stallinga ${ }^{1}$ and Igor Khmelinskii ${ }^{2}$ \\ ${ }^{1}$ Center for Electronics, Optoelectronics and Telecommunications, Faculty of Science and Technology, \\ University of the Algarve, 8005-139 Faro, Portugal \\ ${ }^{2}$ Center of Studies in Chemistry of the Algarve, Faculty of Science and Technology, University of the Algarve, 8005-139 Faro, Portugal
}

Correspondence should be addressed to Peter Stallinga; peter.stallinga@gmail.com

Received 9 April 2014; Accepted 14 July 2014; Published 29 October 2014

Academic Editor: Angelo de Santis

Copyright (C) 2014 P. Stallinga and I. Khmelinskii. This is an open access article distributed under the Creative Commons Attribution License, which permits unrestricted use, distribution, and reproduction in any medium, provided the original work is properly cited.

\begin{abstract}
The primary ingredient of the Anthropogenic Global Warming hypothesis, namely, the assumption that additional atmospheric carbon dioxide substantially raises the global temperature, is studied. This is done by looking at the data of temperature and $\mathrm{CO}_{2}$, both in the time domain and in the phase domain of periodic data. Bicentenary measurements are analyzed and a relaxation model is introduced in the form of an electronic equivalent circuit. The effects of this relaxation manifest themselves in delays in the time domain and correlated phase shifts in the phase domain. For extremely long relaxation time constants, the delay is maximally one-quarter period, which for the yearly-periodic signal means 3 months. This is not in line with the analyzed data, the latter showing delays of $9(-3)$ months. These results indicate a reverse function of cause and effect, with temperature being the cause for atmospheric $\mathrm{CO}_{2}$ changes, rather than their effect. These two hypotheses are discussed on basis of literature, where it was also reported that $\mathrm{CO}_{2}$ variations are lagging behind temperature variations.
\end{abstract}

\section{Introduction}

Currently, one of the biggest worries of our society is the future of the climate. Common belief-supported by an impressive $97 \%$ consensus [1] —is that our planet is heating up at an accelerated rate, caused by the rapid increase in carbon dioxide $\left(\mathrm{CO}_{2}\right)$ concentration in the atmosphere, henceforth called $\left[\mathrm{CO}_{2}\right]$. This increased carbon dioxide finds its origin in human activity; humans burn fossil fuels, thereby injecting large quantities of carbon into the troposphere by converting it into $\mathrm{CO}_{2}$. The $\mathrm{CO}_{2}$ contributes to the greenhouse effect of our atmosphere and it is believed that the anthropogenic $\mathrm{CO}_{2}$ will heat up the planet by up to six degrees during this century (page 45 of IPCC 2007 report [2]). Here we will analyze these ideas and come up with some interesting conclusions. For that, while the subject is the atmosphere, we do not have to go into much detail of atmospheric science. There are observations one can make about climate systems, even without going into technical details. They are in the realm of signal processing and feedback theory.

The model of Anthropogenic Global Warming (AGW) stands or falls with this idea that temperature $T$ is strongly correlated to $\left[\mathrm{CO}_{2}\right]$ by the so-called greenhouse effect. Even though it is highly questionable to summarize the entire climate system in these two scalar properties-both $\left[\mathrm{CO}_{2}\right]$ and $T$ show fractal-like variations in space and timethis is often done. Serious doubt is immediately found by anybody analyzing the data. The contribution of $\mathrm{CO}_{2}$ to the greenhouse effect can easily be estimated to be about $3.6 \%$ [3] . The total greenhouse effect is also well known; without our atmosphere our planet would be 32 degrees colder, as can be calculated on basis of a radiation balance and albedo of our planet. This makes the $\mathrm{CO}_{2}$ greenhouse effect only 1 kelvin in a simple analysis. We arrive at a similar value if we use statistics and do a linear regression on contemporary $\left[\mathrm{CO}_{2}\right]$ and temperature data, the maximum of the effect we can thus expect in a linear model when doubling the concentration artificially by burning up fossil fuels [4]. This is below the Global Warming models even if we were to use a linear model. Moreover, it is unlikely that the effects are linear. The system is more likely to be sublinear. That is because the greenhouse effect is governed by absorption of light which is expected to follow the Beer-Lambert Law: the absorption is highly sublinear; twice as much $\mathrm{CO}_{2}$ will not cause twice as much 
absorption. The classical Arrhenius' Greenhouse law actually states that the forcing is logarithmic.

Yet, later models incorporating nonlinear positivefeedback effects as proposed by many climate scientists do predict a super-linear behavior and come up with an estimate of between 1.1 and 6.4 degrees heating for the next century as caused by our carbon dioxide injection into the atmosphere [2]. The positive feedback can come from secondary effects such as an increase in water in the atmosphere, a strong greenhouse agent, or a $\mathrm{CO}_{2}$-degassing of ground in the permafrost regions when these thaw.

Climate scientists are basing these conclusions mainly on research of the so-called finite-elements type, dividing the system in cells that interact, the same way the weather is studied. Such systems are complicated, but by tuning the processes and parameters that are part of the simulations they manage to explain the actual climate data to an impressive accuracy, as evidenced by the quality of pictures presented in the official climate reports; see, for example, the IPCC 2007 report where simulation and reality are as good as indistinguishable [2], and, moreover, alarmingly, they conclude that the recent rise in temperature can only be attributed to $\mathrm{CO}_{2}$. Yet, the problem with such simulations is that even if they do simulate the past, no insight is gained into the system unless the simulations themselves are analyzed; that is, we have just deferred the problem. This kind of simulations, if not properly analyzed and interpreted, could be in fact a devastating tool for the progress of understanding.

From a philosophical point of view, the fact that the past was explained very accurately does not guarantee the same quality for the prediction of the future. It does not prove that the model is correct. The climate system is chaotic. Small deviations in parameters and initial conditions or assumptions made in the simulations can cause huge changes in the outcome. This is easily explained in an example from electronics. If we have a chaotic circuit with, for instance, critical feedback, we can go to our SPICE or Cadence simulator and find the parameters of our components that exactly explain the behavior of our circuit, so far so good. The problem is that if we now go back and switch on the same circuit, we will get a different result. (Just take an operational amplifier with $100 \%$ positive feedback, in the saturated state, the output voltage may reach the positive supply voltage as easily as the negative supply voltage, either case can be simulated.) An additional problem is that even the parameters themselves are not constant and seem to change without any apparent reason, for instance, the El Niño phenomena in the climate. This is one of the reasons electronic engineers talk about "phase margins," the zone in Nyquist plots, real versus imaginary parts of gain, that should be avoided because the circuit will become unpredictable even if it may be simulated perfectly.

In fact, recent temperature data fall way out of the prediction margins of earlier models. In view of the discussion above, this does not come as a surprise. Where extrapolation from the 2007 IPCC report predicted 2011 to be a year with an anomaly of close to one degree $\left(0.95^{\circ} \mathrm{C}\right.$ is our personal estimate based on Figure 2.5 of the IPCC 2007 Report), in reality the anomaly is closer to zero. Since 1998, the hottest year in recent history, the planet has actually been cooling, something that was not foreseen by the predictions of 2007 where a continuing exponential increase in temperature was forecasted by the then generally accepted model. The scientific community is now going back to its drawing boards and fine-tunes its models to new perfection and manages to simulate the new data as well. This is a Bayesian way of doing science and is significantly less reliable. The correctness of this statement is evidenced by the fact that there now apparently exist many models that explain the data up to a certain point in time; every correction of the model that is still consistent with earlier data proves this. Apparently, there is a manifold of models that can explain certain data quite satisfactorily (but that diverge for future predictions). In view of this, one should be reluctant in making strong claims about the correctness of any model.

Just like in the weather, where the same simulationevaluation techniques are used, we can only hope to get the predictions reasonably under control after thousands of iterations between predictions and reality. Each iteration takes about the amount of time as the prediction span-one week with the weather, 30 years with the climate. Honestly speaking, before we get it right, it will take at least some hundreds of centuries if we uniquely use the approach of finite-elements calculations on supercomputers. In the meantime, we should not see any climate models as proven indisputable facts. A skeptic approach to any scientific model is not an illness; it is an essential ingredient in science. Theories are correct until proven wrong. Ideas that stand up to scrutiny are more likely to be correct than ideas one is supposed not to question.

Still, undeniably, a strong correlation is found between the $\mathrm{CO}_{2}$ concentrations and the temperatures as measured by gas-analysis in drillings in ice shelves; see, for example, the data of the PANGAEA project suggesting that one is the function of the other for the past hundreds of thousands of years [5]. That is a very strong point.

However, proving only statistical correlation, it is not clear from these data which one comes first. Generally, correlation does not mean causation: in particular, in our case, are temperature variations the result of $\left[\mathrm{CO}_{2}\right]$ variations, or vice versa? While the data are consistent with the model of AGW, they cannot serve as proof of these models. In fact, upon closer scrutiny, the temperature always seems to be ahead of $\mathrm{CO}_{2}$ variations. See Figure 1, where a detail of the temperature and $\left[\mathrm{CO}_{2}\right]$ history as measured by icetrapped gases is plotted, picturing the most blatant example of this effect. A simulation (dashed line) is also shown with an exponential-decay convolution of $15 \mathrm{kyr}$, quite adequately reproducing the results. Indermühle and coworkers [6] made a full statistical analysis and find a value of $900 \mathrm{yr}$ for the delay and moreover note that "this value is roughly in agreement with findings by Fischer et al. who reported a time lag of $\mathrm{CO}_{2}$ to the Vostok temperature of $(600 \pm 400)$ yr during early deglacial changes in the last 3 transitions glacial-interglacial [7]." This is inexplicable in the framework of Global Warming models and we honestly start having some legitimate doubts.

The apparent time lag may possibly be due to a calibration problem of the measurements, and indeed corrections 


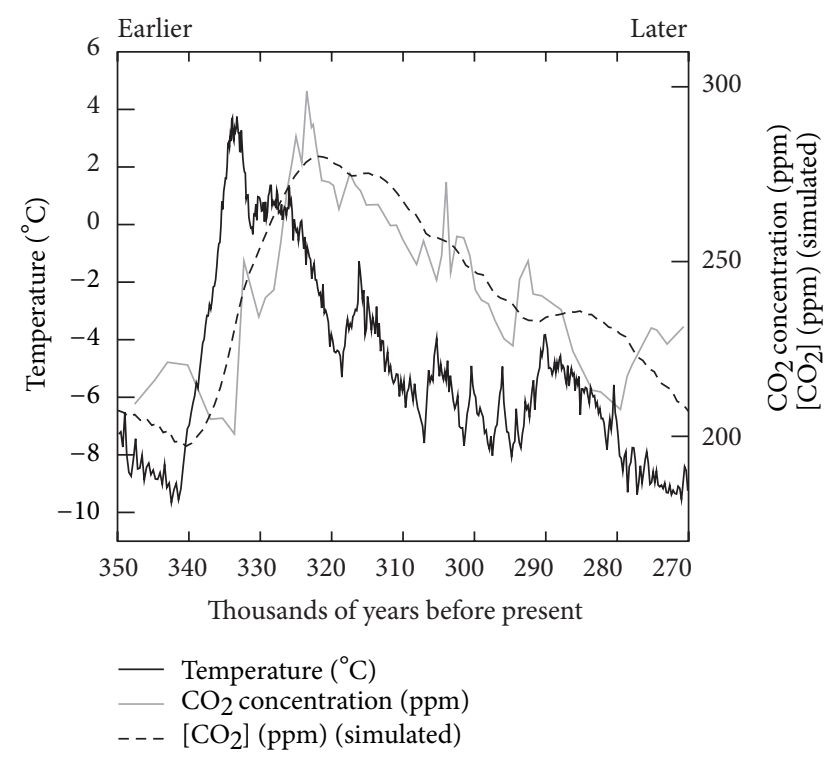

Figure 1: Detail of data of ice shelf drilling correlating the $\mathrm{CO}_{2}$ concentration and temperature. It is obvious that $\mathrm{CO}_{2}$ lags behind the temperature. This is consistently the case. A simulation is shown (dashed line) of a convolution of the temperature with a delay of 15 thousand years.

have been made to the data since then, to make $\left[\mathrm{CO}_{2}\right]$ variations and temperature variations coincide. While these corrections are the result of circular reasoning-where the magnitude is found by modeling the behavior of ice based on climate models and the climate models are based on the ice behavior-these corrections are not even sufficient to remove our doubts. If the correlations are true and we continue to claim that temperature variations are the result of $\left[\mathrm{CO}_{2}\right]$ variations, something is still not correct. The Vostok data of Figure 1 show a sensitivity of 10 degrees for $50 \mathrm{ppm}\left[\mathrm{CO}_{2}\right]$. Note that contemporary $\left[\mathrm{CO}_{2}\right]$ variations are of the order of $80 \mathrm{ppm}$ rise from the preindustrial value. We are thus in for a 16-degree temperature-rise. The fact that we did not reach that level means that either $\mathrm{CO}_{2}$ is not climate forcing, or that there is a delay between $\left[\mathrm{CO}_{2}\right]$ variations (cause) and temperature variations (effect). To then get a rough idea of the magnitude of this delay, in 25 years, only $2.5 \%$ ( 0.4 of 16 degrees) of this rise occurred. The relaxation time is thus (25 years $) / \ln (0.975)$, which is about 1000 years. These are backof-the-envelope calculations-any "real" values used for the calculation could anyway be debated by anybody. Yet, the outcome will always be more or less this order of magnitude. In other words, either the Vostok plots should show a delay between $\left[\mathrm{CO}_{2}\right]$ and $T$ of the order of 1000 years, or the carbon dioxide is not climate forcing. The data, however, show a delay of -900 years [6] or zero, the latter value resulting from questionable corrections. As far as we know, no correction was proposed to result in the $+1000 \mathrm{yr}$ delay necessary to explain contemporary behavior.

What is more, modern correlation figures such as those given in Figure 1 also include methane $\mathrm{CH}_{4}$ (available at NOAA Paleoclimatology [8]) and, remarkably, this methane shows the same correlation with $\left[\mathrm{CO}_{2}\right]$ and $T$. This leaves us flabbergasted. We know that methane is also (assumed to be) a strong climate-forcing greenhouse agent. The enigma is, then, how did the information from the $\left[\mathrm{CO}_{2}\right]$ variations percolate to $\left[\mathrm{CH}_{4}\right]$ variations? Was this information from $\left[\mathrm{CO}_{2}\right]$ transmitted to the methane through the temperature variations? In other words, $\left[\mathrm{CH}_{4}\right]$ variations are the result of $T$ variations, rather than their cause? Then we may equally assume that $\left[\mathrm{CO}_{2}\right]$ variations are the effect of $T$ variations rather than their cause. That should not be considered farfetched.

There are several mechanisms that may explain such an inverse phase relation, such as outgassing of $\mathrm{CO}_{2}$ (and $\mathrm{CH}_{4}$ ) from the warming oceans and thawing permafrost; the correlation between $\left[\mathrm{CO}_{2}\right]$ and $\left[\mathrm{CH}_{4}\right]$ then stems from a common underlying cause. If that is the case, artificially changing the $\mathrm{CO}_{2}$ in the atmosphere will not change the temperature of our planet, just like heating up a can of soda will liberate the gases contained therein into the atmosphere, while increasing the concentrations of gases above the can of soda will not raise its temperature. This unidirectional relation between temperature and gas concentrations is what is called Henry's Law; the ratio of concentrations of gas dissolved in the liquid and mixed in the air above it in equilibrium is a parameter that depends on temperature. AlAnezi and coworkers have studied this effect in more detail in a laboratory setup under various conditions of salinity and pressure, and so forth [9]. For $\mathrm{CO}_{2}$ in and above water an increase in temperature will cause outgassing with a proportionality that is consistent with the correlation found by the historic correlations of global temperature and $\mathrm{CO}_{2}$ in the atmosphere. Also, Fischer and coworkers find the delay of $\left[\mathrm{CO}_{2}\right]$ relative to $T$, as discussed above, likely caused by this ocean outgassing effects [7] and find that at colder times, the delay is longer, which is itself consistent with Arrheniuslike behavior of thermally-activated processes, characteristic of the vast majority of chemical reactions occurring in nature. In the presence of an alternative explanation, there is room for doubt in the AGW ideas that increased $\left[\mathrm{CO}_{2}\right]$ will cause an increased temperature.

Inspired by this uncertainty in the (Anthropogenic) Global Warming model, we tried to see if we can find more evidence for this failure of the cause-and-effect idea. We looked at the recent historic climate data (from just before the AGW model prevalence) and meticulously measured $\left[\mathrm{CO}_{2}\right]$ data and came to the same conclusion, as we will present here.

\section{Results}

We started with the data of a climate report from before the Global Warming claims. We deem these data more reliable since they were for sure not produced under the tutelage of a political committee (IPCC). At least we are more convinced about the neutrality of the scientists reporting these data. Moreover, the work contains all the useful data and these are even available online. The ideas presented here do not need recent data and thus we refrained from looking at them altogether. 


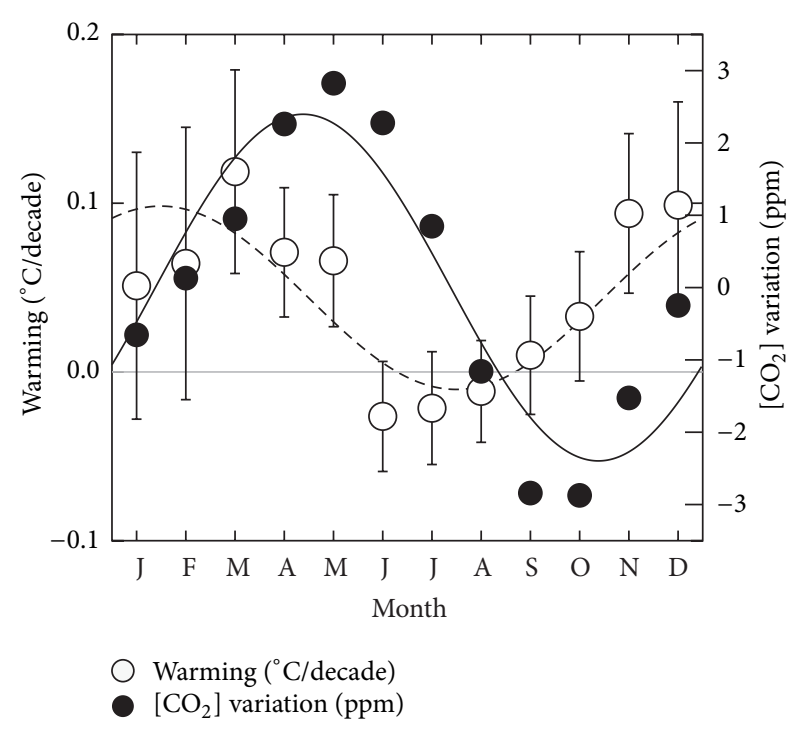

FIgURE 2: Distribution of global warming (degrees per decade) between 1851 and 1991 (source: Balling et al. [10]) and $\mathrm{CO}_{2}$ concentrations (measured at Mauna Loa, source: NOAA [13]) over a year. The dashed and solid lines are sinusoidal fits to the data of temperature and $\left[\mathrm{CO}_{2}\right]$, respectively.

The authors of the work, Balling and coworkers [10], analyzed the global warming (without capitals because it is not the name of a model) and concluded the following: "our analysis reveal a statistically significant warming of approximately $0.5^{\circ} \mathrm{C}$ over the period 1751 to 1995 . The period of most rapid warming in Europe occurred between 1890 and $1950, \ldots$ no warming was observed in the most recent half century." Note that at the onset of the Global Warming ideas, no warming was observed that can be correlated to the (accelerated) increase of $\left[\mathrm{CO}_{2}\right]$. Note also that since 1998 it has not warmed up at all, as confirmed by satellite data (1998 was the warmest year) [11], in spite of the continuing exponential increase in atmospheric $\mathrm{CO}_{2}$ [12]. The temperature seems to be unaffected by the anthropogenic $\mathrm{CO}_{2}$.

Balling and coworkers then went on to analyze the increase in temperature as a function of the time of the year for the data between 1851 and 1991. They calculated for each of the twelve months the increase in temperature. They found a distribution as given in Figure 2 (open circles).

This figure based on the data of Balling is again remarkable. The first thing we note is that, while there has been an average of warming, this is not spread equally over the year. In fact, summer months have become cooler. Without knowing the underlying reason, this is remarkable, since $\left[\mathrm{CO}_{2}\right]$ has increased in all months. There are seasonal fluctuations of the $\mathrm{CO}_{2}$ concentrations; see the black dots which represent the monthly $\left[\mathrm{CO}_{2}\right]$ fluctuations relative to the yearly average at the Mauna Loa site (source: NOAA, visited 2008 [8]). These rapid fluctuations are mainly attributed to biological activity (the Northern hemisphere has more land and in colder times-in winter-more plants are converted into $\mathrm{CO}_{2}$ and in warmer times-in summer-more photosynthesis takes place converting $\mathrm{CO}_{2}$ into biomass, i.e., $\left[\mathrm{CO}_{2}\right]$ is a natural function of temperature). Part of the fluctuations, however, is attributed to human activity (in winter the Northern hemisphere-where more people live-is cold and humans thus burn more fuel to warm their houses, i.e., $\left[\mathrm{CO}_{2}\right]$ is a function of temperature). As a side note, these two things show us that it is very straightforward to understand how $\left[\mathrm{CO}_{2}\right]$ can be a function of temperature, in these cases through biological activity, including that of humans, in this case resulting in a rapid inverse proportionality (warmer $\rightarrow$ less $\mathrm{CO}_{2}$ ). Other long-term processes such as degassing of oceans can have opposite effects, that is, warmer $\rightarrow$ more $\mathrm{CO}_{2}$. While we bear this in mind, we will continue the reasoning of Anthropogenic Global Warming and assume an opposite correlation, that is, temperature is a function of $\left[\mathrm{CO}_{2}\right]$, and analyze the oscillations. We will show that this assumption is inconsistent with the data.

While the natural oscillations have always existed and thus do not result in seasonal oscillations of global warming, the human-caused fluctuations should be represented in the temperature fluctuations. What we would expect in the framework of AGW is that all months have warmed up (because of general injection of anthropogenic $\mathrm{CO}_{2}$ into the atmosphere), but winter months a little bit more (because of seasonal fluctuations of these injections). As a response to the sinusoidal $\left[\mathrm{CO}_{2}\right]$ oscillations, a sinusoidal oscillation in temperature is to be expected that is (i) offset vertically by an amount to make it fully above the zero line; (ii) offset (delayed in time) by a time that can be up to 3 months maximum, as will be discussed here. Neither is the case.

Comparing the monthly fluctuations in temperature increase with monthly fluctuations in $\left[\mathrm{CO}_{2}\right]$ we see again that the latter lags behind, this time by about 3 months (to be precise, fitting sine curves to the data gives a difference of 2.9 months). One might think that the temperature lags behind 9 months - after all, months are periodic-but upon second thought, this is not possible. This is best explained in a relaxation model.

Electronic engineers model things with electronic circuits and this case of temperature and $\mathrm{CO}_{2}$ is also very adequately studied by such circuits. Using an equivalent electronic circuit does not mean that the processes are electronic, but that they can be modeled by such circuits, as in an analog computer. (The appendix gives the mathematical link between a relaxation model and the equivalent electronic circuit.)

In this case we have a model between driving force (either $\left[\mathrm{CO}_{2}\right]$, as we are wont to believe, or temperature $T$ ) and the response (resp., $\mathrm{T}$ or $\left[\mathrm{CO}_{2}\right]$ ). For instance, an increase in $\left[\mathrm{CO}_{2}\right]$ will cause an increase in $T$ by the greenhouse effect. This is necessarily a simple relaxation system, where the changes of the force cause the system to be off-equilibrium until a new equilibrium is reached. This restoring of the equilibrium comes with a certain relaxation time. The reasons for relaxation can be various. For instance, $\mathrm{CO}_{2}$ has to diffuse to places where it can do its temperature effect. There can even be more than a single relaxation process, with a complex kinetics similar to a multistage nuclear decay. The fact is that one of the relaxation times is dominant, and we can describe the relaxation by a single relaxation time (i.e., the sum of all relaxation times). As long as there is no resonance in the 
system (something that can only be achieved with positive feedback) it will behave as described here.

We will model our climate system with a simple electronic relaxation system consisting of a resistance and a capacitance, $R$ and $C$, respectively; see Figure 3. The product of the two yields the relaxation time, $\tau=R C$. At the entrance of this system we connect our oscillating driving voltage $V_{i}(t)$ (representing, e.g., $\left[\mathrm{CO}_{2}\right]$ oscillations), in which $t$ is time. The response is measured as the charge $Q(t)$ in the capacitor which represents, for instance, the temperature variations. This charge is also measured by the output voltage by the standard capacitor relation $V=Q / C$. Thus our output voltage $V_{o}(t)$ represents the response (e.g., temperature).

Applying a sinusoidal input signal, $V_{i}(t) \propto \sin (2 \pi f t) \propto$ $\left[\mathrm{CO}_{2}\right](t)$ (with $f$ the frequency of oscillation), we get a sinusoidal wave at the output, with the same frequency, but with a phase at the output that is not equal to the phase at the input signal, $V_{o}(t) \propto \sin (2 \pi f t+\theta)$. The phase difference $\theta$ is directly and uniquely determined by the relaxation time of the system $\tau$ and the oscillation frequency $f$; see Figure 3 .

For very low oscillating frequencies, the system can easily relax and the phase of the output signal is equal to that of the input signal. For increased frequencies or for increased relaxation times the system has difficulty accompanying the driving force. The amplitude at the output drops and starts lagging behind the input. The maximum phase difference for infinite frequencies or infinite relaxation time is exactly onequarter period.

In our case our oscillating period is one year. One-quarter period is thus 3 months and that is the maximum delay we can expect between driving force and response. For relaxation times much longer than the oscillating period of one year, that is actually the delay one expects. The delay time provides information about the system.

As an example, the comparable system of solar radiation and temperature-comparable in that the oscillating period is one year and both deal with the weather and climate-has a delay of one month; the solar radiation and temperature oscillate with one year period, but the warmest day is nearly everywhere one month after the day with the most daylight and the on average coldest day is one month after the day with least daylight. In Figure 3(c) we see that the relaxation time of the \{radiation $\rightarrow$ temperature system therefore must be about 0.1 year (1.2 months). In the plot this is indicated with a dot.

We can get a similar estimation value of the relaxation time of the atmosphere temperature through daily oscillations. As a rough figure, the temperature drops by about 4 degrees at night in about 8 hours after the sun has set. Assume that the relaxation upon this step-like solar radiation is a simple exponential (situation b shown in the appendix) and would finish eventually at close to absolute zero (say 10 kelvin) and starts at $290 \mathrm{~K}$ (thus a total amplitude of $280 \mathrm{~K}$ ): 4 degrees in 8 hours, we solve the equation

$$
(280 \mathrm{~K}) \times \exp \left(-\frac{(8 \text { hours })}{\tau}\right)=(280-4) \mathrm{K},
$$

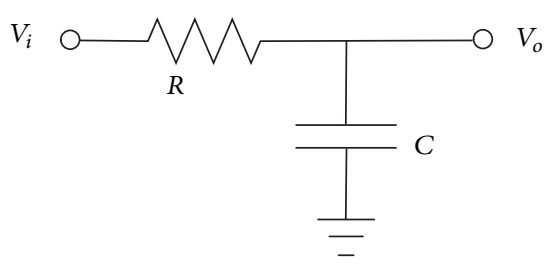

(a)

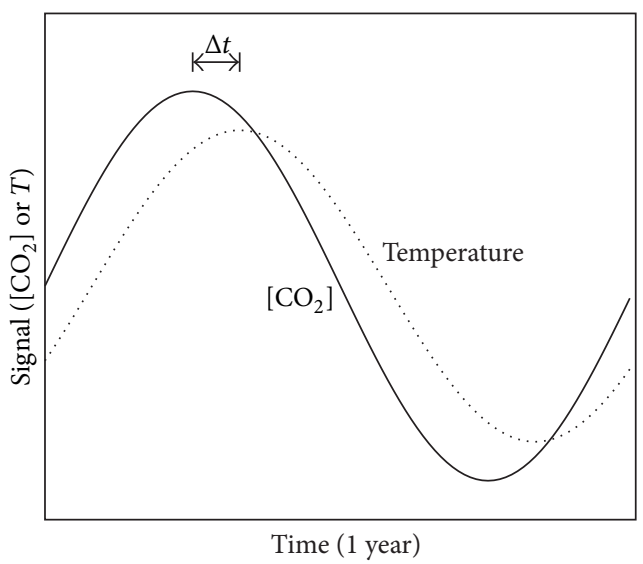

(b)

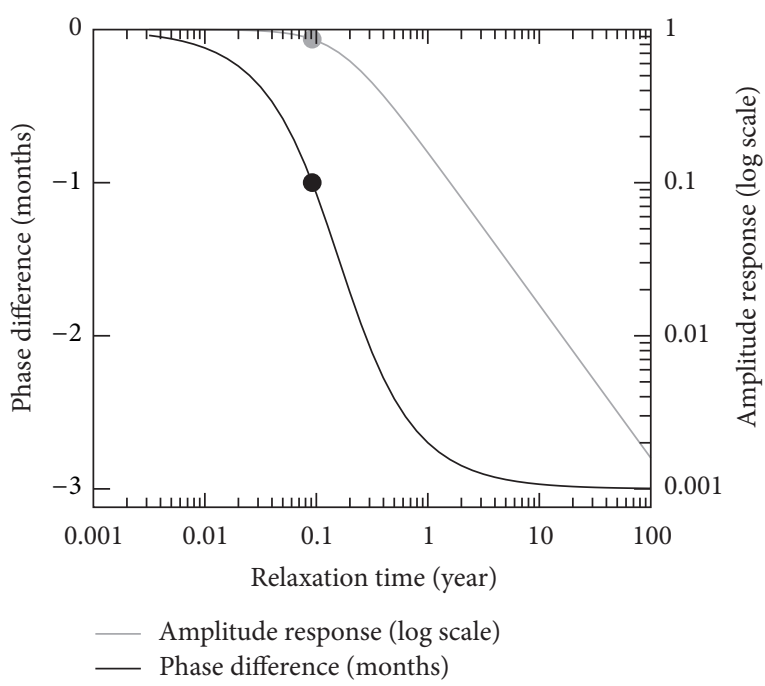

(c)

Figure 3: Relaxation RC system. (a) Equivalent circuit. (b) Temporal response. (c) Phase difference (dark curves) and amplitude (gray curve, log scale) of response. Note that the maximum phase difference is 3 months. The dot represents the radiation-temperature system, where the warmest (coldest) day is about one month after the "longest" ("shortest") day, indicating a relaxation time of about 0.1 year (1.2 months).

which yields 23 days, close to the value found above from yearly oscillations.

Going back to the data of $\left[\mathrm{CO}_{2}\right]$ and temperature (Figure 2) we can now understand the behavior, that is, the phase difference, but only if we assume the temperature to be the driving force. For instance, for some reason the temperature has increased more in winter months, and, as 
a result, to the natural $\left[\mathrm{CO}_{2}\right]$ oscillations has been added a component with a maximum in spring months. The alternative, $\left[\mathrm{CO}_{2}\right]$ being the driving force and a delay of 9 months (3 quarter periods), is mathematically not possible. Another explanation, which we do not consider as a valid alternative, is that the temperature might be lagging behind $\left[\mathrm{CO}_{2}\right]$ if it has a negative gain, that is, $\left[\mathrm{CO}_{2}\right]$ increments lower the temperature. This negative sign of the gain would add another $180^{\circ}$ phase shift and a total apparent phase shift of $270^{\circ}$ would be possible. This goes even more against AGW models, although we do not see an easy physical explanation for how $\mathrm{CO}_{2}$ might lower the temperature.

\section{Discussion}

This simple analysis opposes the hypothesis that $\left[\mathrm{CO}_{2}\right]$ is causing serious temperature rises. As said, the model assumes that no resonance occurs that can possibly cause longer delay times. This, in our opinion, is a valid assumption since resonance is not likely. First of all, for this strong positive feedback, resonance effects should be observable, which experimentally is not the case. Although many climate scientists have proposed positive feedbacks as discussed in the introduction and they make heavy use of them in order to explain and model the needed nonlinear behavior of the greenhouse effect, this goes against intuition. In a chaotic system these feedback factors are then extremely critical. Scientists of any plumage, when making such simulations, know this: if they change their parameters just slightly (sometimes even in the scale of the numerical resolution of their floating point numbers), the outcome can be hugely different.

There is also an experimental argument against positive feedback factors, namely, the conscientious satellite measurements; see, for instance, the work of Lindzen and Choi [14], Spencer [15], or Wielicki et al. [16]. These, in fact, prove a negative feedback in the climate system. Without feedback, in standard theory, if Earth warms up (by global warming in a radiation imbalance), the temperature rises and the outward Earth radiation increases by a certain amount, until establishing a new equilibrium. In the AGW model, a positive feedback of the the following form is used: if the temperature increases, the outward Earth radiation is less than that predicted by standard theory or the incoming solar radiation increases because of reasons like cloud (non)forming, thus increasing the temperature even further. The contrary can also happen: in negative feedback, if the planet heats up by a radiation imbalance for whatever reason, new channels of Earth radiation can be opened or incoming solar radiation blocked (for instance, by increased cloud cover), thus reducing the temperature with respect to standard theory. As demonstrated by the scientists mentioned above, the Earth climate is a negative-feedback "autostabilizing" system, while they do not identify any specific feedback mechanisms. This is also in agreement with the fact that, whereas the conditions on our planet have significantly changed over the geological history (the sun for instance has been $25 \%$ less bright than today), the climate has been rather stable, always restoring from climate perturbations to median values instead of saturating in extreme values; the latter would be expected in a thermal-runaway positivefeedback climate system. Note that, if large positive feedback exists, the temperature is unstable and will change until it saturates, that is, until negative feedback becomes important. In other words, it is technically not even possible that we are in a positive-feedback situation, considering the stable temperatures. (Compare this to the positive-feedback of a shopaholic-buying always makes him buy even more-his funds are acceleratingly depleted or his credit increasingly rising, until the banks put a lid on his spending, i.e., negative feedback.) We must be in a negative-feedback situation and Lindzen and Choi, Spencer, and Wielicki et al. have proven this by measurements. Negative feedback was already argued to be significant when the consensus of the scientists was for a global cooling; see the work of Idso [17].

Additional arguments against positive feedback come from the fact that every day, and every year, the temperature is brought off equilibrium. At night it cools down and in the daytime it warms up. In winter it cools down and in summer it warms up. These temperature disturbances are much larger and much faster than those that may have been produced by greenhouse gases (20 degrees/day or 30 degrees/year versus 0.7 degrees/100 years). The same accounts for $\mathrm{CO}_{2}$ disturbances. The human-caused $\mathrm{CO}_{2}$ seems insignificant compared to the large and noisy emissions naturally occurring on this planet (only the accumulated effect of the tiny human-originated $\mathrm{CO}_{2}$ is supposed to have an effect). To give an idea, Segalstad established that of the current rise in $\left[\mathrm{CO}_{2}\right]$ levels relative to the preindustrial level only $12 \mathrm{ppm}$ is attributable to human activity while $68 \mathrm{ppm}$ is attributed to natural phenomena [18]. These fluctuations are also visible in the extensive summary of Beck [19] and show that even in recent history the $\left[\mathrm{CO}_{2}\right]$ levels were sometimes higher than the modern values, while as everyone knows, the human emissions have monotonously increased, showing that these huge fluctuations can only have a natural origin. Relevant for the discussion here, the fluctuations would rapidly push the climate off equilibrium if it were unstable.

Yet, in spite of these huge disturbances, both in temperature and $\mathrm{CO}_{2}$, the equilibrium is restored every day and every year and every century. Had the earth climate been a positive-feedback system, in summer or in winter the temperature would have been in a runaway situation, unrecoverable in the following compensating half-period. Apparently the system can recover very easily and repeatedly from such huge disturbances. The reason is that the climate is a negative-feedback system that stabilizes itself. This is an unavoidable conclusion.

One might think that the seasonal fluctuations are too fast to be causing a runaway scenario and that before the system runs away it already recovers. That is a misapprehension: changes cannot be too fast. If the system is intrinsically unstable, it will be unstable. If starting oscillations are much faster than the response time of the system, the effective amplitude is reduced, but in a runaway system they will be amplified up to the point of saturation. The system can only be stable if the feedback factor at that specific frequency is not positive. Look at it like this: in the first half of the year, it is hot 
and the system tries to runaway. In the second half of the year it is colder and it will restore, but it has a minute memory that the temperature has already run off a little in the first half and the second half therefore does not compensate completely. In the first year we remain with a tiny temperature offset. Once this offset is introduced, the system will runaway. Of course, it can runaway in both directions. Chance will determine which one, but if the system is unstable (positive feedback), the system will run away. Like the metastable system of a ball placed on top of a hill. It can only stay there in the absence of noise or any fluctuation in general. In conclusion, only negative feedback makes sense.

Relevant to the current work, such negative feedback will make any delay longer than $1 / 4$ period impossible. Thus, the fact that we find a delay close to a quarter period means that (i) the temperature signal is the origin for $\left[\mathrm{CO}_{2}\right]$ signal (or the two are uncorrelated) and (ii) the relaxation time $\tau$ linking the two is (much) longer than the period (12 months) of oscillation.

Moreover, even if positive feedback were present, for the resonance itself to be significant, the oscillating frequency needs to be close to the resonance frequency, that is, 12 months. It is highly unlikely that the natural frequency of the climate- $\left[\mathrm{CO}_{2}\right]$ system is close to the 12 -month-periodic driving force, even more so since also the long-term icedrilling data need to be explained somehow, where delays of several thousands of years are observed. In our analysis, relaxation times of several thousands of years will explain both the ice-drilling data and the yearly temperature and $\left[\mathrm{CO}_{2}\right]$ oscillations.

Finally, the set of data we used is rather limited. We only used data presented by Balling et al. that ends at the end of the 20th century. Moreover, they only have data from the Northern Hemisphere. Future research should tell if the ideas presented here can stand up to scrutiny when more recent data and pan-global data are used. As a note in proof, Humlum et al. [20] have recently investigated correlation between temperature and $\left[\mathrm{CO}_{2}\right]$ variations on the time scale of decades, similarly concluding that $\left[\mathrm{CO}_{2}\right]$ changes are delayed in relation to temperature and can therefore not be the reason for temperature changes.

\section{Conclusion}

In conclusion, the idea tested here that $\left[\mathrm{CO}_{2}\right]$ is the cause of temperature changes does not pass our signal analysis. It goes a little too far to say that what we present here is proof for the opposite, namely, that $\left[\mathrm{CO}_{2}\right]$ is the effect of temperature, but our analysis does not contradict this. Future will tell if such a hypothesis may be postulated with some confidence.

\section{Appendix}

\section{The Mathematics of Relaxations}

In simple relaxation models the (negative) change of a quantity is proportional to the magnitude of the remaining quantity. Simple examples are nuclear decay, in which the change of number $N$ of atoms at a certain time $t$ is given by $d N(t) / d t=-\alpha N(t)$, or the velocity $v$ of an object under friction is given by $d v(t) / d t=-\beta v(t)$ ( $\alpha$ and $\beta$ positive constants). From experience, and by solving the differential equation, we know that such systems show exponential decay, $N(t)=N_{0} \exp (-\alpha t)$ and $v(t)=v_{0} \exp (-\beta t)$, respectively.

Now, we can take a function of time $f(t)$ that is the driving force of another quantity, expressed by the response function $g(t)$, the cause and the effect, respectively. We can decompose the function $f$ into an integral of Dirac-delta functions. The response to each delta function is given by the function $d(t)$. Assuming linearity, the total response is then a convolution:

$$
\begin{aligned}
g(t) & =\int_{-\infty}^{\infty} d(s) u(s) f(t-s) d s \\
& =\int_{0}^{\infty} d(s) f(t-s) d s,
\end{aligned}
$$

where the Heaviside function $u(s)(u(s)=1$ for $s>$ 0 and 0 otherwise) was used to force the causality; the response $d(s)$ can only come after the driving force. (Note that nonlinearities will not change the sign of these calculations, i.e., a delay cannot become an advance.) For instance, if the response function is an exponential decay, as mentioned above,

$$
g(t)=\int_{0}^{\infty} g_{0} \exp (-\alpha s) f(t-s) d s
$$

Substituting a delta-function at $t=0$ for the driving force $f$ will reproduce the exponential decay:

$$
\begin{aligned}
g(t) & =\int_{0}^{\infty} g_{0} \exp (-\alpha s) \delta(t-s) d s \\
& =\int_{0}^{\infty} g_{0} \exp (-\alpha[t-s]) \delta(s) d s \\
& =g_{0} \exp (-\alpha t) u(t) .
\end{aligned}
$$

In other words, the response to a "spike", a delta function at $t=0$ is an exponential decay with an amplitude $g_{0}$ and time constant $\tau=1 / \alpha$. The response to a Heaviside (step) function $f(t)=u(t)$ is then given by

$$
\begin{aligned}
g(t) & =\int_{0}^{\infty} g_{0} \exp (-\alpha s) u(t-s) d s \\
& =\int_{0}^{t} g_{0} \exp (-\alpha s) d s \\
& =\frac{g_{0} u(t)[1-\exp (-\alpha t)]}{\alpha} .
\end{aligned}
$$




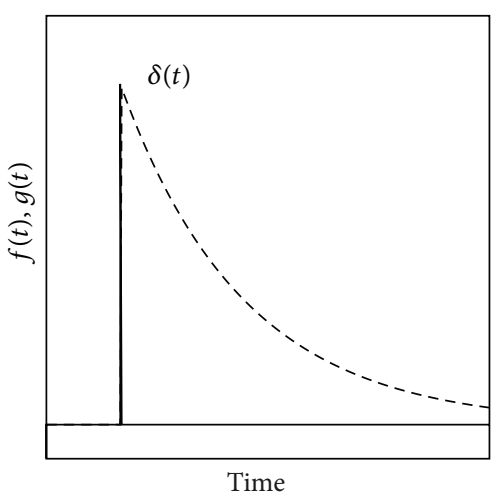

(a)

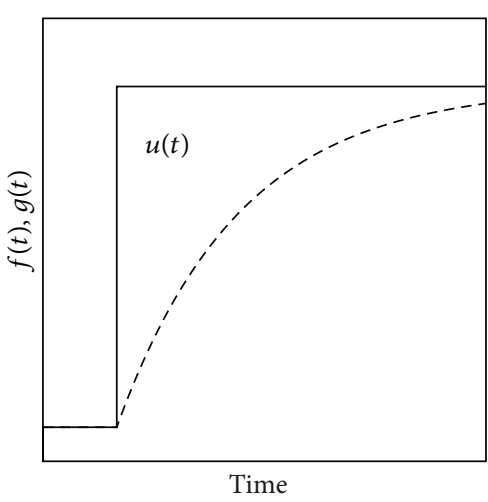

(b)

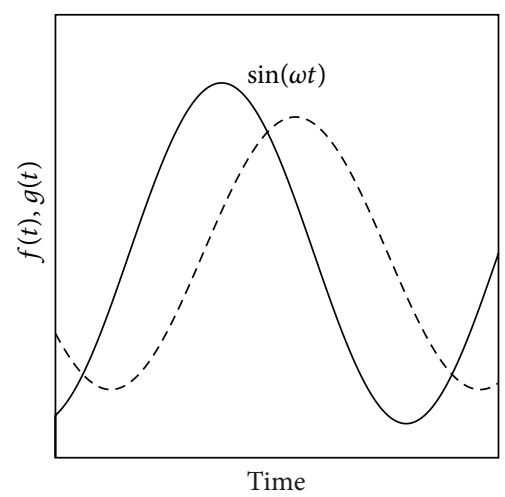

(c)

Figure 4: Cause and effect functions, $f(t)$, solid lines, and $g(t)$, dashed lines, for relaxation systems, with three different driving-force functions: (a) $f(t)=\delta(t)$, (b) $f(t)=u(t)$, and (c) $f(t)=\sin (\omega t)$.

More interesting-more relevant for our work-is the case of a sinusoidal driving force. This can now easily be calculated by substituting the driving-force function $f$ into (A.2):

$$
\begin{gathered}
f(t)=f_{0} \sin (\omega t), \\
g(t)=\int_{0}^{\infty} g_{0} \exp (-\alpha s) f_{0} \sin [\omega(t-s)] d s \\
=\frac{f_{0} g_{0}}{\alpha^{2}+\omega^{2}}[\alpha \sin (\omega t)-\omega \cos (\omega t)] \\
=\frac{f_{0} g_{0}}{\sqrt{\alpha^{2}+\omega^{2}}} \sin \left(\omega t-\tan ^{-1}\left[\frac{\omega}{\alpha}\right]\right) .
\end{gathered}
$$

For the second step in (A.6) Gradshteyn and Ryszik [21] was used. Figure 4 shows these three cases of driving forces and response functions. Figure 1 shows a simulation with the driving function $f(t)$ equal to the measured temperature and a delay of $\tau(=1 / \alpha)=15 \mathrm{kyr}$, which results in a quite good representation of the $\left[\mathrm{CO}_{2}\right]$ curve.

An electronic circuit such as that presented here has these properties of exponential response to a Heaviside function and linearity and the response of (A.6). For this reason, such (virtual) circuits are widely used in simulations of phenomena including phenomena far away from electronics. The interesting and relevant conclusion of (A.6) is that the maximum phase shift is $90^{\circ}$ and this occurs for frequencies that are much higher than the relaxation speed, $\omega \gg \alpha$.

\section{Conflict of Interests}

The authors declare that they do not have any conflict of interests. This research was supported by no grant. It received no funding whatsoever, apart from the authors' salaries at the university where they work. They are not members of any climate committees (political or other); they are not linked to companies or NGOs, financially or otherwise. This is an independent work that does not necessarily represent the opinion of the authors' university or that of their government(s).

\section{References}

[1] J. Cook, "Quantifying the consensus on anthropogenic global warming in the scientific literature," Environmental Research Letters, vol. 8, no. 2, Article ID 024024, 2013.

[2] Intergovernmental Panel on Climate Change, Climate Change 2007: Synthesis Report, 2007, http://www.ipcc.ch/publications_ and_data/publications_ipcc_fourth_assessment_report_synthesis_report.htm.

[3] Monte Hieb, 2011, http://www.geocraft.com/WVFossils/TableOfCont.html.

[4] P. Stallinga, De Mythe van Klimaatsveranderingen, Lulu, 2010.

[5] PANGAEA, 2009, http://www.pangaea.de.

[6] A. Indermühle, E. Monnin, B. Stauffer, T. F. Stocker, and M. Wahlen, "Atmospheric $\mathrm{CO}_{2}$ concentration from 60 to $20 \mathrm{kyr}$ BP from the Taylor Dome Ice Core, Antarctica," Geophysical Research Letters, vol. 27, no. 5, pp. 735-738, 2000.

[7] H. Fischer, M. Wahlen, J. Smith, D. Mastroianni, and B. Deck, "Ice core records of atmospheric $\mathrm{CO}_{2}$ around the last three glacial terminations," Science, vol. 283, no. 5408, pp. 1712-1714, 1999.

[8] NOAA, "Global Mean Monthly Surface Temperature Estimates for the Base Period 1901 to 2000," 2012, http://www.ncdc.noaa .gov/cmb-faq/anomalies.php.

[9] K. Al-Anezi, C. Somerfield, D. Mee, and N. Hilal, "Parameters affecting the solubility of carbon dioxide in seawater at the conditions encountered in MSF desalination plants," Desalination, vol. 222, no. 1-3, pp. 548-571, 2008.

[10] R. C. Balling, R. S. Vose, and G.-R. Weber, "Analysis of long-term European records: 1751-1995," Climate Research, vol. 10, pp. 1751-1995, 1998, http://www.int-res.com/articles/cr/10/ c010p193.pdf.

[11] Average global temperatures through time, http://www.data360 .org/dsg.aspx?Data_Set_Group_Id=1655\&count=25.

[12] "Earth System Research Laboratory," 2011, http://www.esrl.noaa .gov/gmd/ccgg/trends/.

[13] NOAA, Online data, http://www.esrl.noaa.gov/gmd/ccgg/ trends/.

[14] R. Lindzen and Y.-S. Choi, "On the det ermination of climate feedbacks from ERBE data," Geophysical Research Letters, vol. 36, no. 16, p. L16705, 2009. 
[15] R. Spencer, "Satellite and climate model evidence against substantial manmade climate change," submitted to Journal of Climate, http://www.drroyspencer.com/research-articles/satelliteand-climate-model-evidence/.

[16] B. A. Wielicki, T. Wong, R. P. Allan et al., "Evidence for large decadal variability in the tropical mean radiative energy budget," Science, vol. 295, no. 5556, pp. 841-844, 2002.

[17] S. B. Idso, "Long-term stabilization of earth's surface air temperature by a negative feedback mechanism," Archives for Meteorology, Geophysics, and Bioclimatology B, vol. 31, no. 3, pp. 211-219, 1982.

[18] T. V. Segalstad, "Carbon cycle modelling and the residence time of natural and anthropogenic atmospheric $\mathrm{CO}_{2}$ : on the construction of the "Greenhouse Effect Global Warming" dogma," http://www.co2web.info/ESEF3VO2.pdf.

[19] E.-G. Beck, "Evidence of variability of atmospheric CO2 concentration during the 20th century," 2008, http://www.biomind .de/realCO2/.

[20] O. Humlum, K. Stordahl, and J. Solheim, "The phase relation between atmospheric carbon dioxide and global temperature," Global and Planetary Change, vol. 100, pp. 51-69, 2013.

[21] I. S. Gradshteyn and I. M. Ryszik, Table of Integrals, Series and Products, Formula 3.893/1, 6th edition, 2000. 

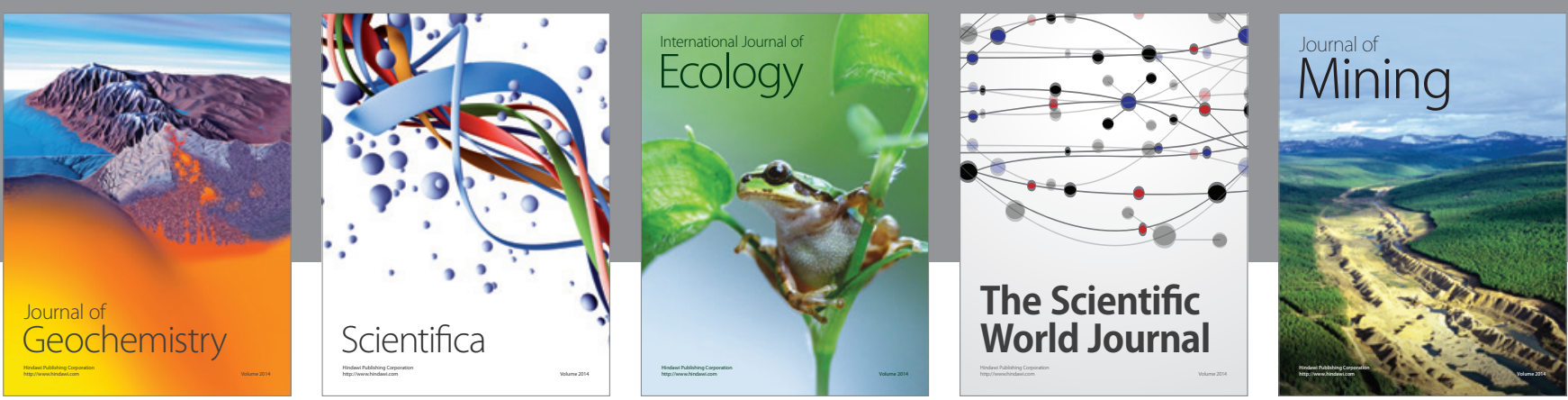

The Scientific World Journal
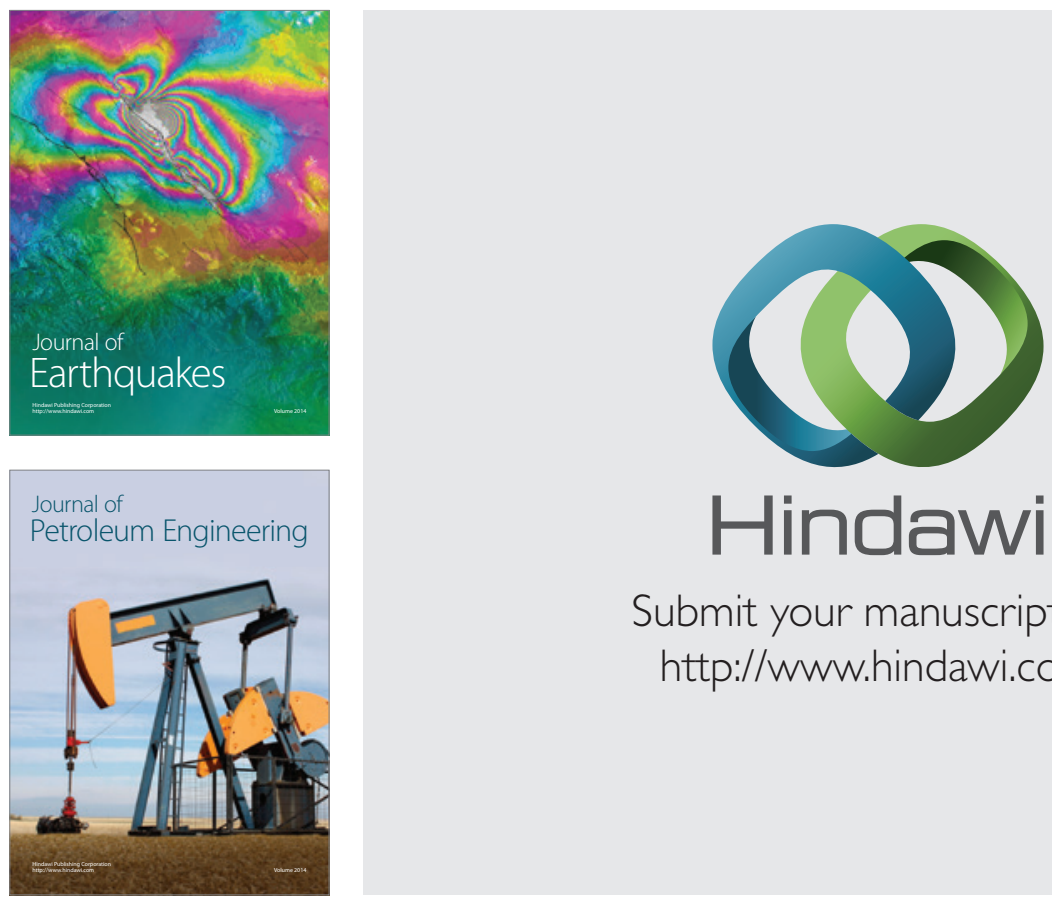

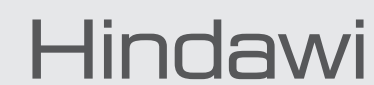

Submit your manuscripts at

http://www.hindawi.com
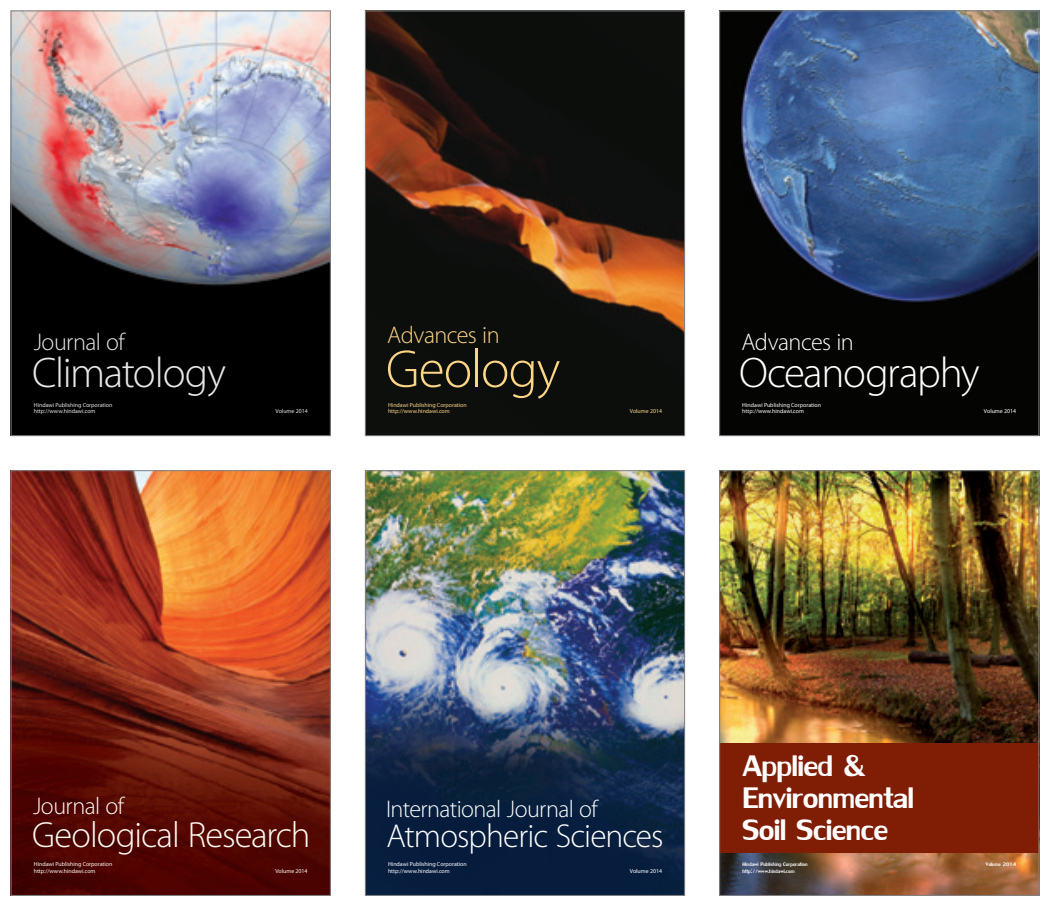
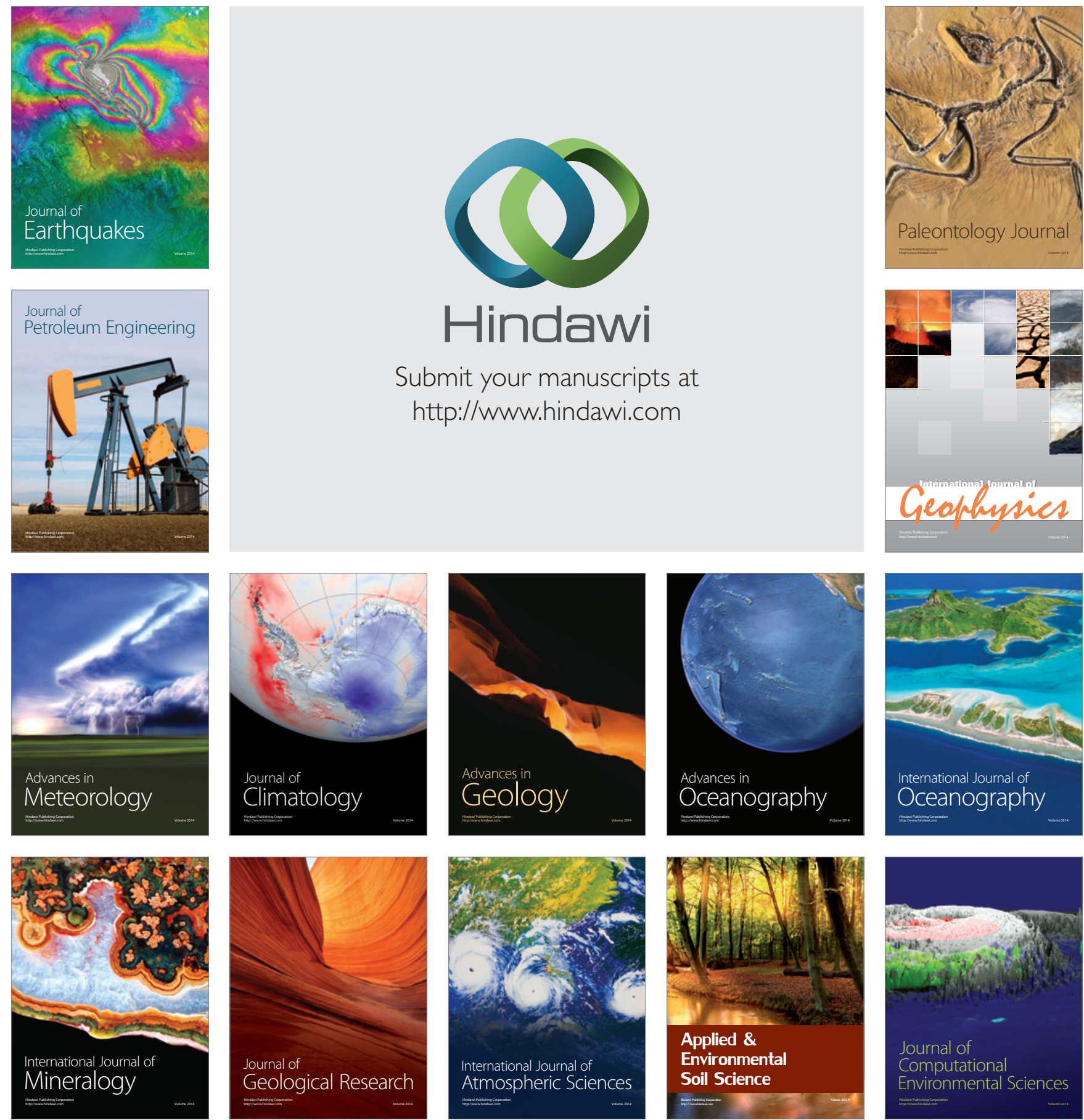